\title{
The effect of plurality and obesity on betamethasone concentrations in women at risk for preterm delivery
}

\author{
Cynthia GYAMFI, MD, Lisa MELE, Sc.M., Ronald J. WAPNER, MD, Catherine Y. SPONG, \\ MD, Alan PEACEMAN, MD, Yoram SOROKIN, M.D., Donald J. DUDLEY, M.D., Francee \\ JOHNSON, R.N., B.S.N., Kenneth J. LEVENO, M.D., Steve N. CARITIS, M.D., Brian M. \\ MERCER, M.D., John M. THORP Jr., M.D., Mary J. O'SULLIVAN, M.D., Susan M. RAMIN, \\ M.D., Marshall CARPENTER, M.D., Dwight J. ROUSE, M.D., Menachem MIODOVNIK, M.D., \\ and Baha SIBAI, M.D. for the Eunice Kennedy Shriver National Institute of Child Health and \\ Human Development Maternal-Fetal Medicine Units Network \\ Departments of Obstetrics and Gynecology at Columbia University, New York, NY; Drexel \\ University, Philadelphia, PA; Northwestern University, Chicago, IL; Wayne State University, \\ Detroit, MI; University of Utah; Utah, Salt Lake City, UT; The Ohio State University, Columbus, \\ $\mathrm{OH}$; University of Texas Southwestern Medical Center, Dallas, TX; University of Pittsburgh, \\ Pittsburgh, PA; Case Western Reserve University, Cleveland, OH; University of North Carolina at \\ Chapel Hill, Chapel Hill, NC; University of Miami Miller School of Medicine, Miami, FL; The \\ University of Texas Health Science Center at Houston, Houston, TX; Brown University, \\ Providence, RI; University of Alabama at Birmingham, Birmingham, AL; University of Cincinnati, \\ Cincinnati, $\mathrm{OH}$; and University of Tennessee, Memphis, TN; The George Washington University \\ Biostatistics Center, Washington, DC; and the Eunice Kennedy Shriver National Institute of Child \\ Health and Human Development, Bethesda, MD
}

\begin{abstract}
Objective-Antenatal corticosteroids (ACS) decrease respiratory distress syndrome in singleton gestations. Twin data is less clear. Obesity and BMI also affect medication distribution volume. We evaluated whether maternal or neonatal cord betamethasone concentrations differed in twin gestations or in obese patients.
\end{abstract}

Study Design-Participants receiving betamethasone in a randomized controlled trial of weekly ACS were identified. We analyzed maternal delivery and cord serum betamethasone concentrations comparing singletons with twins and obese (BMI $\geq 30$ ) with non-obese women.

\begin{abstract}
Results-55 maternal and 45 cord blood samples were available. Unadjusted median maternal serum concentrations appeared paradoxically higher in both twin gestations and the obese. However, after controlling for confounders, there were no differences in betamethasone concentrations in maternal serum or cord blood between singletons and twins ( $\mathrm{p}=0.61 \mathrm{v} \cdot \mathrm{p}=0.14$ ) or non-obese and obese women ( $\mathrm{p}=0.67$ v. 0.12 ).
\end{abstract}

Conclusion-Maternal and umbilical cord blood serum betamethasone concentrations are not different in twin gestations or obese women.

(C) 2010 Mosby, Inc. All rights reserved.

Corresponding Author: Cynthia Gyamfi, MD, Columbia University Medical Center, Department of Obstetrics and Gynecology, Division of Maternal-Fetal Medicine, 622 West $168^{\text {th }}$ Street, PH-16, New York, NY 10032. cg2231@ columbia.edu.

Presented at the Society for Maternal-Fetal Medicine, January 29, 2009, San Diego, CA.

Publisher's Disclaimer: This is a PDF file of an unedited manuscript that has been accepted for publication. As a service to our customers we are providing this early version of the manuscript. The manuscript will undergo copyediting, typesetting, and review of the resulting proof before it is published in its final citable form. Please note that during the production process errors may be discovered which could affect the content, and all legal disclaimers that apply to the journal pertain. 


\section{Keywords}

betamethasone concentration; twins; obesity

\section{INTRODUCTION}

Antenatal corticosteroids are administered to promote fetal pulmonary maturity in pregnancies at risk for preterm delivery between 24 and 34 weeks' gestation. However, the dosing requirements in women with multiple gestations and maternal obesity have not been evaluated. Liggins and Howie[1] described a dose of $12 \mathrm{mg}$ of betamethasone given twice, 24 hours apart, in their seminal paper introducing this treatment. Although this regimen was chosen arbitrarily, it is the same regimen that many practitioners continue to use today, and is endorsed by the American College of Obstetricians and Gynecologists [2] and the NIH Consensus Statement on antenatal corticosteroids [3].

Body composition, blood flow, and binding of plasma proteins are the principal factors that affect the volume of distribution of medication.[4] During pregnancy blood volume increases by $40-45 \%$ on average, and greater increases are noted in twin gestations. [5] This increased blood volume along with the decrease in oncotic pressure found in pregnancy, can alter the volume of distribution of certain medications administered during pregnancy. Antenatal corticosteroids have not reliably been shown to decrease the rate of RDS in twin gestations.[6] It has been hypothesized that the more pronounced physiologic changes in twins compared to singletons may account for this observation.[7]

Similarly, obesity can affect the volume of distribution of medication. An intramuscular injection of betamethasone soluspan contains both betamethasone phosphate, a short-acting, rapidly absorbed compound, and betamethasone acetate, a longer-acting compound with delayed absorption. The drug is then metabolized primarily in the liver, but also in the kidney and surrounding tissue. Blood flow per gram of fat in normal weight individuals is more than blood flow in the morbidly obese, $[8]$ and blood flow influences the volume of distribution. Although obesity does not seem to affect absorption, tissue distribution and drug elimination are changed. This raises concerns as to whether the same concentration of betamethasone is available to the fetus of an obese mother as compared to one that is normal weight. Therefore, we chose to study whether the number of fetuses (singleton or twin) or maternal obesity affects the concentration of betamethasone in maternal serum or fetal cord blood.

\section{MATERIALS AND METHODS}

This is an analysis of biological fluids collected within a randomized, double-blinded, placebo-controlled clinical trial conducted by the Eunice Kennedy Shriver National Institute of Child Health and Human Development (NICHD) Maternal-Fetal Medicine Units (MFMU) Network that evaluated whether weekly injections of betamethasone decreased neonatal respiratory morbidity. Full details of the methods and study design have been previously reported.[9] All participants received one course of betamethasone prior to randomization. As part of the original study, maternal serum was collected at randomization and at delivery. Cord blood was also collected at delivery. These samples were centrifuged and frozen at $-80^{\circ} \mathrm{C}$ for future analysis. The present analysis was confined to participants continuing to receive weekly betamethasone injections who delivered within one week of steroid administration. 
All serum samples were analyzed in a single batch at Anapharm Inc (Québec, Canada). Determinations of betamethasone (Celestone ${ }^{\circledR}$ ) concentrations were made using high performance liquid chromatography with tandem mass spectrometry detection using an assay developed by Anaphram Inc. Specifically, the biological matrix used for the assay included human plasma (with EDTA) in which betamethasone was measured over a concentration range of 0.5 to $50 \mathrm{ng} / \mathrm{mL}$. This method has sensitivity demonstrated at the lower limit of quantitation $(0.500 \mathrm{ng} / \mathrm{mL})$. The quality control (QC) samples measured betametasone at four levels, and they were within $\pm 15 \%$ in accuracy and precision.

Concentrations were calculated using the following softwares: MDS Sciex Analyst software, version 1.4.1. (Applied Biosystems/MDS Sciex, Ontario, Canada) and Thermo Electron Corporation Watson LIMS software, version 7.0.0.01b (Inna Phase Corp., Philadelphia, PA, USA).

The outcomes of interest for this analysis were the concentrations of betamethasone in the maternal serum and in the cord blood. We also analyzed the ratio of maternal serum to cord blood betamethasone concentrations. Univariate analysis was used to evaluate betamethasone concentrations in $\mathrm{ng} / \mathrm{mL}$ between singleton versus twin gestations and between women with prepregnancy BMI $<30$ versus BMI $\geq 30$. Continuous variables were analyzed using the Wilcoxon Rank-Sum test for maternal data and Generalized Estimating Equations (GEE), a regression model that can be used to adjust for correlated observations[10], for infant data. Multivariable linear regression analysis was used to examine the relationship between maternal serum betamethasone and obesity, plurality, gestational age at delivery, number of steroid study courses, and time between the last course of steroids and delivery. GEE regression models were used to examine the relationship between cord blood betamethasone and these covariates. Log transformations of betamethasone levels were used in the regression analyses. Nominal statistical significance was set at a p-value less than 0.05 .

\section{RESULTS}

There were 106 samples available for analysis ( 51 fetal [cord blood] and 55 maternal [delivery blood]). Six of the 51 cord blood samples were insufficient to assess betamethasone concentrations. Therefore, 45 cord blood and 55 maternal samples were analyzed comparing maternal and cord blood concentrations in singleton to twin pregnancies. All but 3 patients delivered secondary to spontaneous preterm labor with or without intact membranes.

Forty-five neonates delivered within one week of betamethasone administration; 30 were from singleton and 15 were from twin gestations. Of the 15, there were 6 twin pairs and 3 infants without samples from their co-twin. In the univariate analysis median maternal serum betamethasone concentrations were similar for singleton $(4.4 \mathrm{ng} / \mathrm{mL}$, Interquartile Range $[\mathrm{IQR}] 2.7,6.7)$ compared to twin $(5.2 \mathrm{ng} / \mathrm{mL}, \mathrm{IQR} 3.1,7.8)$ gestations, $\mathrm{p}=0.49$. Median cord blood betamethasone concentrations were higher in twin gestations, $4.4 \mathrm{ng} / \mathrm{mL}$, IQR 2.5, 8.2, compared to singletons, $1.4 \mathrm{ng} / \mathrm{mL}$, IQR 1.0, 3.0, $\mathrm{p}=0.002$. Mothers pregnant with twins also received fewer courses of steroids than mothers of singletons, median 1 v. 3 courses, respectively, $\mathrm{p}=0.04$. Figure 1 shows concentrations of betamethasone in cord blood for singletons and twins by days from last course. Concentrations of betamethasone decreased over time for both singletons and twins $(\mathrm{p}<0.0001)$. There was a trend towards an increase in the ratio of maternal delivery blood to fetal cord in singletons compared to twins, $3.0 \pm 1.1 \mathrm{ng} / \mathrm{mL}$ v. $2.2 \pm 1.2 \mathrm{ng} / \mathrm{mL}$; but, this finding was not statistically significant, $\mathrm{p}=0.07$. After controlling for the number of days since steroid administration, number of steroid courses received, gestational age at delivery and maternal obesity, there were no differences 
in betamethasone concentrations in maternal serum or fetal cord blood between singletons and twins ( $\mathrm{p}=0.61$ and $\mathrm{p}=0.14$, respectively) (Table 1 ).

Of the 45 cord blood and 55 maternal samples available, 2 mothers with serum available were missing information on BMI. Therefore, the second analysis evaluating the effect of maternal obesity on betamethasone concentrations involved only 53 maternal samples. Forty-one of those were non-obese $(\mathrm{BMI}<30)$ and 12 were obese $(\mathrm{BMI} \geq 30)$. Among the obese group, 8 women had a BMI of $<35,2$ had BMIs between 35 and 40, and 2 had BMIs over 40. None of the women had a BMI over 50. Median maternal serum betamethasone concentrations were $4.3 \mathrm{ng} / \mathrm{mL}$, IQR 3.0,6.1, and $5.0 \mathrm{ng} / \mathrm{mL}$, IQR 2.7, 7.6, for non-obese and obese women, $\mathrm{p}=0.74$, respectively. In both groups, maternal betamethasone concentrations (delivery blood values) decreased over time since last course (Figure 2). Cord blood betamethasone concentrations were available for 43 neonates, from 35 non-obese and 8 obese mothers. These concentrations were also similar in both groups, $1.8 \mathrm{ng} / \mathrm{mL}, \mathrm{IQR}$ $1.2,4.6$, versus $2.5 \mathrm{ng} / \mathrm{mL}$, IQR $0.9,6.5, \mathrm{p}=0.82$. The ratio of maternal serum to cord blood betamethasone concentrations were also similar, $2.7 \pm 1.2 \mathrm{ng} / \mathrm{mL}$ in non-obese compared to $3.4 \pm 1.4 \mathrm{ng} / \mathrm{mL}$ in obese women, $\mathrm{p}=0.43$. After controlling for the number of days since steroid administration, number of steroid courses received, gestational age at delivery and number of fetuses, there was not a significant association between maternal obesity and maternal serum betamethasone $\mathrm{p}=0.67$, or between maternal obesity and maternal cord betamethasone concentrations, $\mathrm{p}=0.12$ (Table 1 ). Additional regression analyses that examined BMI as a continuous, rather than dichotomous, variable still did not demonstrate a significant linear association between BMI and serum betamethasone concentration.

\section{DISCUSSION}

In this analysis we did not find a significant association between betamethasone levels and either plurality or obesity, therefore the dosing used to achieve maternal or fetal serum levels is not likely to explain the apparent inefficacy of betamethasone in decreasing RDS in twin gestations. Ballabh et al., performed a similar study evaluating the pharmacokinetics of betamethasone in singleton and twin pregnancies.[7] They found that the volume of distribution of the drug was not different between singletons and twins, but there was a shorter half-life $(7.2 \pm 2.4$ versus $9.0 \pm 2.7$ hours; $P<.017)$ and a trend towards a longer clearance $(8.4 \pm 6.4$ versus $5.7 \pm 3.1 \mathrm{~L} / \mathrm{h} ; P=.06)$ in twins compared to singletons. In contrast to our study, Ballabh and colleagues did not adjust for the number of days from steroid administration to delivery, although they mention there was a wide variation in this time period. They did not adjust for obesity, but mentioned that the maternal weights in the singleton and twin group were similar. In contrast to their study, we could not measure halflife because maternal serum was not collected serially. Another limitation to our study was the small sample size which limits the interpretation of our results. Due to the small numbers, we were also not able to evaluate more subtle effects of variables such as gestational age or degrees of obesity on betamethasone concentrations.

Maximizing the benefits of antenatal corticosteroids is of particular importance since the rate of preterm birth continues to rise. In 2007, the most recent year for which data are available, the preterm birth rate in the United States was $12.7 \%$; this is a $20 \%$ increase since 1990.[11] Twin pregnancies are at markedly increased risk of preterm delivery, and the frequency of twins has also increased from 24.8 per 1000 live births in 1995 to 32.2 per 1000 in 2005.[12] Although antenatal corticosteroids are routinely administered to twin gestations at risk for preterm delivery, the efficacy data are less robust than that of singletons. A recent Cochrane meta-analysis performed by Roberts and Dalziel showed a non-significant reduction in the rate of RDS in twins after administration of steroids, OR $0.85,95 \%$ confidence interval 0.60 to 1.20 , but this is based on 4 studies with 167 cases and 
153 controls.[6] Our findings suggest that the concentration of betamethasone achieved in maternal serum and fetal cord blood from twin gestations is similar to that of singletons, making betamethasone concentrations an unlikely explanation for the findings of Roberts and Dalziel[6]. It is conceivable that a benefit may be demonstrated if a larger number of twins could be evaluated.

The WHO has called the increasing prevalence of obesity an epidemic.[4] Although there is a biologic plausibility to explain why antenatal corticosteroids may have altered efficacy in obese patients, we are not aware of any prospective studies evaluating the rates of RDS in offspring of obese women.

In conclusion we did not find that betamethasone concentrations in maternal or umbilical cord blood were affected by singleton/twin gestation or by obesity. A prospective, observational cohort study with larger numbers of patients would be ideal to validate our findings and to provide further evidence supporting our conclusions.

\section{Acknowledgments}

Supported by grants from the Eunice Kennedy Shriver National Institute of Child Health and Human Development (HD21410, HD21414, HD27869, HD27917, HD27905, HD27860, HD27861, HD27915, HD34122, HD34116, HD34208, HD34136, HD40500, HD40485, HD40544, HD40545, HD40560, HD40512, HD36801) and M01RR-000080 from the National Center for Research Resources (NCRR) and its content is solely the responsibility of the authors and does not necessarily represent the official views of the NICHD, the National Institutes of Health, and the NCRR.

\section{References}

1. Liggins GC, Howie RN. A controlled trial of antepartum glucocorticoid treatment for prevention of the respiratory distress syndrome in premature infants. Pediatrics. 1972; 50(4):515-25. [PubMed: 4561295]

2. American College of Obstetricians and Gynecologists. ACOG Committee Opinion: Antenatal Corticosteroid Therapy for Fetal Maturation. 2008.

3. NIH Consensus Development Panel on the Effect of Corticosteroids for Fetal Maturation on Perinatal Outcomes. Effect of corticosteroids for fetal maturation on perinatal outcomes. JAMA. 1995; 273(5):413-8. [PubMed: 7823388]

4. Cheymol G. Effects of obesity on pharmacokinetics implications for drug therapy. Clin Pharmacokinet. 2000; 39(3):215-31. [PubMed: 11020136]

5. Cunningham, FG.; Leveno, KJ.; Gilstrap, LC., III; Bloom, SL.; Wenstrom, KD., editors. Williams Obstetrics. 22. McGraw-Hill; New York: 2005.

6. Roberts D, Dalziel S. Antenatal corticosteroids for accelerating fetal lung maturation for women at risk of preterm birth. Cochrane Database Syst Rev. 2006; 3:CD004454. [PubMed: 16856047]

7. Ballabh P, Lo ES, Kumari J, et al. Pharmacokinetics of betamethasone in twin and singleton pregnancy. Clin Pharmacol Ther. 2002; 71(1):39-45. [PubMed: 11823756]

8. de Divitiis O, et al. Obesity and cardiac function. Circulation. 1981; 64(3):477-82. [PubMed: 7261280]

9. Wapner RJ, et al. Single versus weekly courses of antenatal corticosteroids: evaluation of safety and efficacy. Am J Obstet Gynecol. 2006; 195(3):633-42. [PubMed: 16846587]

10. Liang KY, Zeger SL. Regression analysis for correlated data. Annu Rev Public Health. 1993; 14:43-68. [PubMed: 8323597]

11. Hamilton BE, Martin JA, Ventura SJ. Births: Preliminary Data for 2007. Natl Vital Stat Rep. 2009; 57(12):1-23. [PubMed: 19754006]

12. Dimes, Mo. Twin Deliveries: US, 1995-2005. 2009. [cited 2009 April 3]; Available from: http://www.marchofdimes.com/peristats/level1.aspx? $\mathrm{reg}=99 \& \mathrm{slev}=1 \&$ top $=7 \&$ stop $=81 \&$ obj $=1 \& l e v=1 \& \mathrm{dv}=\mathrm{cg}$ 


\section{Appendix}

In addition to the authors, the following subcommittee members participated in protocol development and coordination between clinical research centers (Michelle DiVito, R.N., M.S.N) and study design, protocol/data management, and statistical analysis (Elizabeth Thom, Ph.D.).

In addition to the authors, other members of the Eunice Kennedy Shriver National Institute of Child Health and Human Development Maternal-Fetal Medicine Units Network are as follows:

Columbia University - F. Malone, V. Pemberton, S. Bousleiman

Drexel University - M. DiVito, A. Sciscione, V. Berghella, M. Pollock, M. Talucci

Wayne State University - M. Dombrowski, G. Norman, A. Millinder, C. Sudz, D. Driscoll

The Ohio State University — J. Iams, M. Landon, S. Meadows, P. Shubert

University of Utah - M. Varner, K. Anderson, A. Guzman, A. Crowley, M. Fuller

Northwestern University — G. Mallett

University of Texas Southwestern Medical Center - D. Weightman, L. Fay-Randall, P.

Mesa

Wake Forest University Health Sciences -P. Meis, M. Swain, C. Moorefield

University of Pittsburgh - T. Kamon, K. Lain, M. Cotroneo

Case Western Reserve University - P. Catalano, C. Milluzzi, C. Santori

University of North Carolina at Chapel Hill — K. Moise, K. Dorman

University of Chicago - A. Moawad, P. Jones, G. Mallett

University of Miami — D. Martin, F. Doyle

The University of Texas Health Science Center at Houston - L. Gilstrap, M.C. Day

Brown University - D. Allard, J. Tillinghast

University of Alabama at Birmingham - A. Northen, K. Bailey

University of Cincinnati - H. How, N. Elder, B. Alexander, W. Girdler

University of Tennessee - B. Mabie, R. Ramsey

Eunice Kennedy Shriver National Institute of Child Health and Human Development - D. McNellis, K. Howell, S. Pagliaro

The George Washington University Biostatistics Center - E. Thom, F. Galbis-Reig, L. Leuchtenburg

MFMU Network Steering Committee Chair (Vanderbilt University Medical Center) - S. Gabbe 


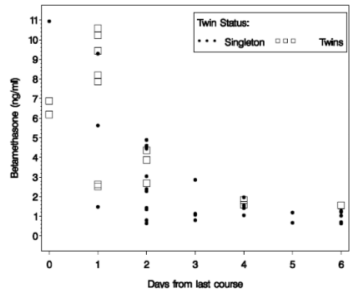

Figure 1.

Betamethasone (Beta) level by days since steroid dose in cord blood in $\mathrm{ng} / \mathrm{mL}$ in singleton versus twin pregnancies 


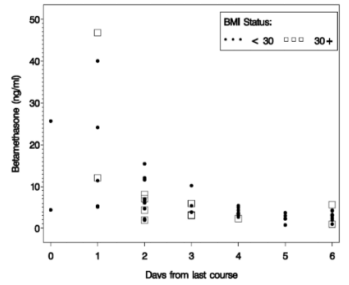

Figure 2.

Betamethasone (Beta) level by days since steroid dose in maternal serum in $\mathrm{ng} / \mathrm{mL}$ in obese versus non-obese pregnant women 


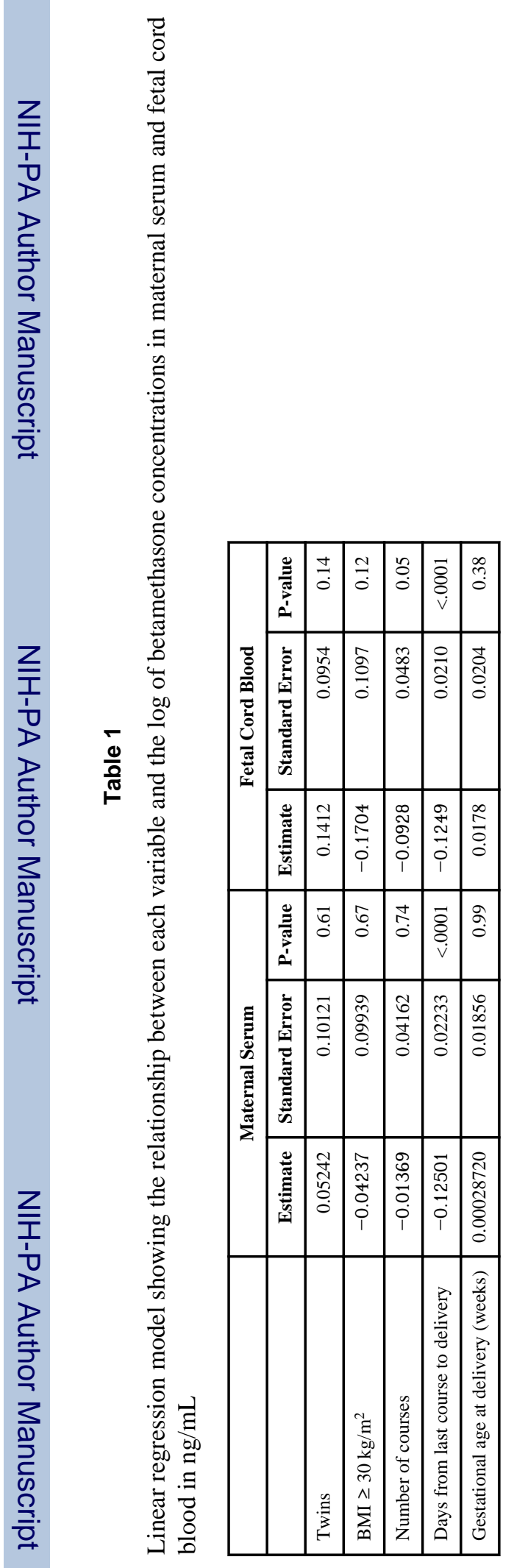

